\title{
Knowledge Management Enablers and Faculty's Knowledge Sharing Behavior in Academic Institutions of Nepal
}

\author{
Bishwash Raj Poudel \\ Lecturer, Faculty of Management, Janapriya Multiple Campus, Pokhara, Nepal \\ Corresponding email: bishwash.raj.poudel@gmail.com
}

Article History

Received 24 April 2021

Revised 19 August 2021

Accepted 2 November 2021

\begin{abstract}
Uncovering the factors that propel knowledge sharing behavior of faculty members in the context of Nepal shall have some practical implication. First it is a high time to move forward the discourse of implementing formalized knowledge management system in Nepal. For this, the study has identified training and development, monetary reward system, trust as significant predictors of knowledge sharing behavior. Moreover, it is a bitter paradox of knowing and not doing. There exists knowing-internalizing-doing-being gap in knowledge management context of Nepal. The core job responsibilities of faculty members may be redefined in the contemporary period where academicians have to transform their students from knowing to doing to being state of excellence.
\end{abstract}

Keywords: Knowledge management, knowledge sharing, KM instrument, KM enablers, knowledge sharing behavior.

\section{INTRODUCTION}

Universities are the repositories of much of the scarcest and valuable human capital that nations possess, capital that is valuable because it is essential to the development of the high technology and techno science necessary for competing successfully in the global economy. The human capital possessed by universities, of course, is vested in their academic staffs. When faculty implement their academic capital through engagement in production, they are engaging in academic capitalism. Their scarce and specialized knowledge and skills are being applied to productive work that yields a benefit to the individual academic, to the public

(C) The Author, published by JRCC, Janapriya Multiple Campus. 
university they serve, to the corporations with which they work, and to the larger society. It is indeed academic capitalism that is involved, both technically and practically (Metcalfe, 2005).

Laal (2011) argued that all organizational inherently store, access, and deliver knowledge in some way. Nevertheless, the question is what value is supplemented to the products and services they deliver by the effective use of the knowledge capital. He added "Higher educational institutions have significant opportunities to apply knowledge management practices to support every part of their mission". Like other sectors, higher educational institutions are also facing the effect of globalization. As a response towards globalization, the institutions hence have to initiate and implement restructuring programs. Some of the visible evidence of globalization is seen in the migration patterns of students and faculties' the development of cross-national education programs such as distance learning initiatives, and increasing internationalization of colleges and universities (Metcalfe, 2005).

Given all the premises that application of knowledge management presents a direct benefit to student, faculty, society and more precisely to the sustainable development of the nation, it is necessary to further explore the enablers of knowledge management, the process and outcome in more concrete manner. The general objective of the study is to examine the individual and organizational factors affecting knowledge sharing behaviors among faculty members in Nepalese higher educational institutions. The knowledge sharing behavior comprises of explicit knowledge sharing: codification strategy and tacit knowledge sharing: personalization strategy. Specifically, the impact of reward system, top management support, training and development and trust on faculty knowledge sharing behavior is examined.

Universities are in fact involved in knowledge business. They are source of innovation for business organization because without knowledge in brain, it is neither possible to generate novel ideas nor to implement or go forth for commercialization. In this mechanism, the role of faculty member comes into interplay because they are primary agents involved in producing innovative brains. This argument can be substantiated from the views of different scholars those emphasized role of people in knowledge management such as "Human capital possessed by university is vested in their academic staffs" (Metcalfe, 2005); "It is people, not system or technology, who know" (Nguyen, 2006); "Knowledge is created through interaction between individuals" (Nonaka \& Takeuchi, 1995). Therefore, the faculty members should share knowledge that are acquired from their formal education, teaching experiences, life experiences, trainings, conferences, seminars, workshops, research works, intuition and insights to other faculty members, students, investors, international community and government. When 
knowledge is hoarded and not shared, it dies with no contribution to society.

Knowledge sharing as a cornerstone of knowledge management should be fostered in a university environment as a culture. However, what we should keep in mind is knowledge sharing is broader concept that emphasizes social interaction for knowledge exchange (Kang, Kim \& Chang, 2008). In addition, Hansen (1999) argued it is about building solid network with others in different work units. Similarly, Davenport (1997) advocated knowledge sharing a voluntary act and distinguished from reporting. Therefore, faculty members cannot be forced to share knowledge. In support of this argument, Bock and Kim (2002) clearly mentioned that "rather than just encouraging or mandating knowledge sharing, fostering the motivation to share knowledge must precede". Therefore, universities should focus on enabling factors for intensifying knowledge sharing. As we all argue, the motivators for sharing knowledge originates from institutional factors, individual factors and social factors. As Malaysia and Indonesia have gone far further in the deployment of knowledge management in higher academic institutions, of course, same can happen in Nepalese context. Knowledge sharing should be promoted in our universities too.

Grant (1996) expressed his view that defining knowledge has intrigued some of the world greatest thinkers from Paulo to Popper without coming up with a clear consensus. Nonaka and Takeuchi (1995) definition of knowledge is far broader in scope and stated as "a dynamic human process of justifying personal belief toward the truth". According to Lam (2000), the knowledge of the firm can be analyzed along two dimensions: the epistemological and the ontological. The previous concerns the modes of expression of knowledge i.e., tacit and explicit knowledge and later relates to locus of knowledge which can reside at the individual or collective levels. Knowledge sharing is beyond simple transfer of new knowledge in which knowledge is seen as an object like a visible product. It is usually a broader concept that emphasizes social interaction for knowledge exchange. Knowledge management is much broader concept that encompasses the creation, accumulation, sharing, and application of information and knowledge (Kang, Kim, \& Chang, 2008).

Drucker (1994) stated that, "Education will become the center of the knowledge society, and the school its key institution. What knowledge must everybody have? What is "quality" in learning and teaching? These will of necessity become central concerns of the knowledge society, and central political issues". Indeed, like any other institutions, prior to formulation and implementation of KM strategy should be clear about one question: "Knowledge to do what?" There are very few studies related to knowledge management in higher educational 
institutions in context of Nepal. Adhikari (2010) lay a foundation for future empirical research in knowledge management in Nepal by providing holistic picture of reality to future prospect of different KM dimensions. The study highlighted that an open institutional culture and good fit between information technology and social relations is required in order to promote knowledge management initiatives in Nepalese perspective.

With a focus on individual level of KM by faculties of universities and colleges and also realizing the caveats that many studies of KM practices related to academic institutions are dominated in the context of developed countries, Gautam (2012) attempted to identify initiatives taken by faculties of Tribhuvan University(TU) on knowledge management with an aim to suggest strategies for quality education. The findings of the study was in consistent with Adhikari(2010) as both study stressed that there are very few occassions to share knowledge except classrooms and lack of incentives to promote knowledge sharing behavior. Chalise and Darroch (2016) advocated the need for understanding philosophical developments: logical empiricism; naturalized nature of epistemology; brain, mind and knowledge; connectionist psychology, regarding theory of knowledge before the knowledge itself.

Knowledge sharing is an ill-defined concept. Scholars use several similar concepts interchangeably without conceptual clarity. Knowledge sharing is often used interchangeably with knowledge transfer and knowledge management. However, knowledge sharing is beyond simple transfer of new knowledge in which knowledge is seen as an object like a visible product. It is usually a broader concept that emphasizes social interaction for knowledge exchange. However, knowledge sharing is part of the initiative of knowledge management. Knowledge management is much broader concept that encompasses the creation, accumulation, sharing, and application of information and knowledge (Kang, Kim, \& Chang, 2008).

Effective knowledge sharing among organizational members requires immediate attention to the antecedents of knowledge sharing that make people collaborate and share their knowledge for the eventual improvement of organizational performance. This is because the degree to which organizational members are willing to share their knowledge relies heavily on systematic organizational support of those identified antecedents. According to Grant (1996) knowledge sharing is defined as process of strengthening organizational effectiveness by maximizing the utilization of knowledge shared among members of the organization. Hansen (1999) defined knowledge sharing as a process of building a solid network with others in differrent work units. Gupta and Govindarajan (2000) described it as a process of identification, outflow, transmission, and inflow of knowledge in an organization. 
As the $21^{\text {st }}$ century unfolds, many people regard the strategic management of knowledge resources as one of the key factors for sustainable competitive advantages. In particular knowledge sharing is perceived to be the most essential process for knowledge management. However, sharing knowledge is often unnatural. People will not share knowledge as they think their knowledge is valuable and important. Hoarding knowledge and looking suspiciously upon knowledge from others are the natural tendency and this natural tendency is difficult to change (Davenport, 1997).

Indeed, Bock and Kim (2002) argued that rather than just encouraging or mandating knowledge sharing, fostering the motivation to share knowledge must precede. Due to such psychological tendency of people, it is necessary to develop an understanding of the factors that support or constrain the individual's knowledge sharing behavior in the organization, and how they eventually influence the knowledge sharing behaviors. Bock and Kim (2002) further defined knowledge sharing as the transmission or distribution of individual knowledge in an organization. This study adopted Bock and Kim's definition of knowledge sharing. In other words, this study focuses on individual level of knowledge sharing, which is the unit of analysis of the present study.

To substantiate, Nonaka and Takeuchi (1995), in their definitive work 'The Knowledge Creating Company' were among the first to recognize the importance of individual employees in the knowledge creation process. According to them, knowledge creation should be viewed as a process whereby knowledge held by individuals is amplified and internalized as part of an organization's knowledge base. Thus, knowledge is created through interaction between individuals at various levels in the organization. Nonaka and Takeuchi argued that organizations cannot create knowledge without individuals, and unless individual knowledge is shared with other individuals and groups, the knowledge is likely to have limited impact on organizational effectiveness.

Davenport (1997) defined sharing as a voluntary act and distinguished it from reporting. Reporting involves the exchange of information based on some routines or structured formats. Sharing, on the other hand, implies a conscious act by an individual who participates in the knowledge exchange even though there is no compulsion to do so.

Predictors incorporated in model were deemed to affect knowledge sharing behavior without mechanism in between the relationship. Limited conceptual and empirical explicit knowledge on knowledge sharing and management issue addressing faculty member and institution itself indicates a sign of early stage of formalized knowledge management system 
in Nepal. Incorporating knowledge sharing behavior as variable of interest and attempting to measure impact of reward, top management support, training and development and trust has as far as in knowledge and consciousness shall be first of its kind in Nepalese scholastic community. The main objective of this study is to examine faculty members' perceptions on enablers of knowledge management contribute to their knowledge sharing behavior among colleagues.

\section{Research Hypothesis}

On the basis of literature review, following hypotheses are formulated for the study

$\mathbf{H}_{1} \quad$ Reward system positively affects the faculty knowledge sharing behavior in Nepalese higher educational institutions.

$\mathbf{H}_{2}$ Support from top management positively affects the faculty knowledge sharing behavior in Nepalese higher educational institutions.

$\mathbf{H}_{3} \quad$ Training and development positively affects the faculty knowledge sharing behavior in Nepalese higher educational institutions.

$\mathbf{H}_{4} \quad$ There is positive relationship between trust and faculty knowledge sharing behavior in Nepalese higher educational institutions.

\section{DATA AND METHODS}

The study used an analytical research design as it investigated the impact of knowledge management enablers such as reward system, top management support, training and development, and trust on faculty knowledge sharing in Nepalese higher educational institutions. Self-administered questionnaires were developed using a 7-point Likert scale (i.e., ranging from $1=$ strongly disagree to $7=$ strongly agree). The primary segment of the instrument included a total of 21 items.

The total population for the study comprised of teachers working under management faculty of higher educational institutions of Nepal. Higher education in Nepal is provided by the universities. Bachelors and Masters are the two major levels of study offered by the universities. The share of management faculty in terms of student enrollment in Nepalese higher education is about $40 \%$. Tribhuvan University share on total management students in Nepalese higher educational institutions is $80 \%$. Similarly, Pokhara University, Purbanchal University, Kathmandu University, Far Western University and Mid-Western University share on total management students in Nepalese higher educational institutions is about $11 \%, 6 \%$, 
$2 \%, 1 \%$ and $1 \%$ respectively. Likewise, Out of 935 campuses offering management education in Nepal, large proportion of campuses (i.e. 45\%) are located in Bagmati Province. Despite of all this information, the total number of management teachers working in constituent, community and private campuses of Nepalese universities is not found to be published. The total number of teaching staffs in the constituent campuses of the Nepalese universities was 9154.

Hinkin, Tracey, and Enz (1997) offered a $N^{*} q$ rule, attributable to Schwab (1980), for determining the appropriate sample size where $\mathrm{N}$ refers to the number of cases, subjects or respondents and q refers to the total number of items in measurement instrument. The subject per item ratio suggested was 10:1, which means 10 respondents for each item. The minimum sample size identified and ensured on the basis of the 10:1 ratio was not less than 210 (i.e. 10 respondents per total 21 scale items). Therefore, the sample size for the study 304 was more than the required minimum sample size of 210. Austin and Steyerberg (2015) concluded that in case of fitting multivariable or multiple linear regression models, analysts should require a minimum of only two subjects per variable (SPV) in the model to guarantee unbiased estimation of coefficients and adjusted $\mathrm{R}^{2}$ values but higher numbers for adequate statistical power. Correspondingly, Green (1991) offered a rule, attributable to Marks that specified a minimum of 200 subjects for any regression analysis. Moreover, The sample size for the study is 304 can be substantiated from the fact as many recent studies under same theme have taken sample sizes around 250 and have used multiple regression and structural equation modeling in order to fulfill the research objectives (Lee, 2018; Naeem, Mirza, Ayyub, \& Lodhi, 2017; Kumaraswamy \& Chitale, 2012; Omerzel, Biloslavo, Trnavcevic, \& Trnavcevic, 2011; Masa'deh, Shannak, Maqableh, \& Tarhini, 2017; Boateng, Dzandu, \& Tang, 2014; Youssef, Saheem, \& Youssef, 2017; Sohail \& Daud, 2009; Allameh, Zare, \& Davoodi, 2011).

Considering in terms of number of enrollment through purposive sampling framework at initial stage, the data was collected from three of the major universities in terms of student enrollment in management faculty which of them are Tribhuvan University, Pokhara University and Kathmandu University respectively. The respondents for the study comprise of both permanent and temporary faculty members of 15 large campuses in terms of number of student enrollment.

The data for the study was collected through visiting different campuses by meeting teaching faculty members in faculty room. Moreover, online questionnaire was also prepared and distributed to some respondents in acquaintance that fits with the qualified respondents of 
the study through the use of information reported in the website of colleges and universities, and social media. In that perspective, the data collection method used in the study was a survey method. Prior to conducting a final survey, for the purpose of the pilot testing, 10 questionnaires were distributed to the teaching faculty members randomly as Hill (1998) suggested 10 to 30 participants for pilots in survey research. The faculties were requested to fill up the questionnaire before or after their class as per their convenience. In some cases, the questionnaires were filled in the places were there used to be informal gathering of faculty members such as in tea shops or places other than faculty rooms. Some of the full-time faculty members holding administrative positions were requested to fill up the questionnaire at their own offices. A single campus was visited multiple times to increase the number of respondents from respective institution. It was found that teaching faculty members were so busy on their schedules and some portion of the faculty members denied to fill up the questionnaire as they were in a hurry to take classes in other institution. In general, it was relatively easy to collect the data in campuses where the student enrollment rate was high because in such campuses there was large number of teaching faculty available in transit in faculty rooms and in other respective places of college premise. However, it was very difficult to collect the data in private university and colleges due to strict internal administrative procedures. In this context, it was learned that personal relationship with the college representative makes the data collection process easier as they would provide necessary support and assistance in the process of data collection. The faculty members who have already passed M.Phil. or doctorate degree cooperated actively in the phase of data collection.

The data obtained from the respondents is analyzed using multiple regression method. Before, conducting multiple regression analysis, the reliability of scale would be tested and all the assumptions of the multiple regressions such as normal distribution of residuals, absence of outliers, homoscedasticity and multicollinearity is also verified. Moreover, the independent sample $t$ test was carried in order to test the relationship between control variables and knowledge sharing behavior.

After screening the data set for missing values and outlier, reliability analysis was conducted using Cronbach's alpha, a measure of internal consistency and an indication of how closely related a set of items are as a group. 


\section{Table 1}

Cronbach's Alpha and Items Included in Each Construct

\begin{tabular}{ll}
\hline Construct & Cronbach's alpha $(\alpha)$ \\
\hline Reward system (RS) & 0.704 \\
Top management support (TMS) & 0.895 \\
Trust (TR) & 0.771 \\
Training and development (TD) & 0.774 \\
Knowledge sharing behavior (KSB) & 0.779 \\
\hline
\end{tabular}

The values of Cronbach's Alpha are within the range of 0.704 to 0.895 for all constructs included in the model. Thus, according to the Interpretation of Cronbach's Alpha Values presented in (Mwape \& Mumba, 2012), when the Cronbach's alpha values falls within $0.7 \leq<$ 0.8 , the level of internal consistency is regarded as acceptable. Therefore, the reward system, trust, training and development and knowledge sharing behavior have acceptable level of internal consistency. The top management support falls under the category of $0.8 \leq<0.9$ which is interpreted as good in terms of level of internal consistency. Furthermore, Mwape \& Mumba (2012) elaborated that Cronbach's alpha estimates the reliability of a measuring instrument or scale by determining the internal consistency of the instrument or the average correlation of the items measuring the same variable.

\section{RESULTS AND DISCUSSION}

\section{Table 2}

Profile of Respondents $(n=304)$

\begin{tabular}{llll}
\hline Characteristics & & Number & Percent \\
\hline Gender & Male & 269 & 88.50 \\
Marital status & Female & 35 & 11.50 \\
& Single & 25 & 8.20 \\
Age(in years) & Married & 279 & 91.80 \\
& Less than 30 & 15 & 4.90 \\
& $30-40$ & 139 & 45.70 \\
& $41-50$ & 104 & 34.20 \\
& $51-60$ & 37 & 12.20 \\
University & More than 60 & 9 & 3.0 \\
\hline
\end{tabular}




\begin{tabular}{llll}
\hline \multirow{4}{*}{ Type of campus } & Pokhara University & 72 & 24.0 \\
& Kathmandu University & 16 & 5.0 \\
\multirow{5}{*}{ Education } & Constituent & 131 & 43.0 \\
& Community & 62 & 20.0 \\
Length of service & Private & 111 & $37 \%$ \\
& Masters & 216 & 71.10 \\
& MPhil & 74 & 24.30 \\
& Doctorate & 14 & 4.60 \\
Employment status & Less than 5 years & 51 & 16.80 \\
& 5-10 years & 104 & 34.20 \\
& $11-20$ years & 122 & 40.10 \\
Nature of employment & More than 20 years & 27 & 8.90 \\
& Professors & 9 & 3.0 \\
& Associate professors & 10 & 3.30 \\
& Others & 285 & 93.70 \\
& Permanent & 124 & 40.80 \\
& Temporary & 180 & 59.20 \\
\hline
\end{tabular}

Table 3

Importance and Priority Ranking

Knowledge management enablers

Mean Mean

ranking

\section{A) Reward system}

$\begin{array}{lll}\text { My institution offers rewards for sharing knowledge with colleagues. } & 3.27 & 21\end{array}$

$\begin{array}{lll}\text { I am driven by rewards for sharing knowledge with colleagues. } & 4.04 & 17\end{array}$

$\begin{array}{lll}\text { The rewards offered for sharing knowledge with colleagues are } & 3.3 & 20\end{array}$

attractive.

Rewards are an essential motivation for knowledge sharing in general. $\quad 5.71 \quad 1$

B) Top management support

$\begin{array}{lll}\text { College management team thinks that encouraging knowledge sharing } & 4.67 & 10\end{array}$ with colleagues is beneficial.

College management team always support and encourage faculty to

$4.39 \quad 13$ share their knowledge with colleagues. 
College management team provides most of the necessary help and

resources to enable faculty for sharing knowledge with colleagues.

College management team is keen to see their faculty members happily 4.83

sharing knowledge with colleagues.

\section{C) Trust}

I believe my colleagues are knowledgeable and competent in their area. $5.5 \quad 2$

I have full confidence in the skills of my colleagues. $\quad 5.29 \quad 4$

When I face difficulties at work, I know my colleagues will help me. $\quad 5.26 \quad 5$

$\begin{array}{lll}\text { My colleagues do not try to deceive me for their own profit. } & 5.09\end{array}$

\section{D) Training and development}

When faculty starts new job in this institution, they are given enough $\quad \begin{aligned} & 3.58 \\ & 19\end{aligned}$

guidance and training.

My institution is committed to ongoing training and development of $\quad 4.36 \quad 14$ academic staff

The training and development I received from this institution has

improved my performance.

Knowledge sharing behavior

I share knowledge with my colleagues actively on informal occasions. $5.3 \quad 3$

I share knowledge with my colleagues actively on formal occasions. $\quad 4.9 \quad 8$

I share knowledge with my colleagues through written communication. $4.32 \quad 15$

I use my institutional information system or database to store my $\quad 4.01 \quad 18$

knowledge.

My colleagues share knowledge actively on formal occasions. $\quad 4.4 \quad 12$

My colleagues share knowledge actively on informal occasions. $\quad 5.15 \quad 6$ 


\section{Table 4}

Grouping of Items into Agreement and Disagreement

\begin{tabular}{|c|c|}
\hline $\begin{array}{l}\text { Disagreement } \\
\text { (Highest to Lowest) } \\
\text { (Below neutral: mean } \\
\text { value 4) }\end{array}$ & $\begin{array}{l}\text { Agreement (Highest to Lowest) } \\
\text { (Above neutral: mean value 4) }\end{array}$ \\
\hline Offering of reward for & Reward as an essential motivator (Item no 4) \\
\hline knowledge sharing & Trust on knowledge of colleagues (Item no 9) \\
\hline (Item no 1$)$ & Knowledge sharing on informal occasion (Item no 16) \\
\hline Attractiveness of & Trust on skills of colleagues (Item no 10) \\
\hline reward offered against & Colleagues will help on difficulty (Item no 11) \\
\hline $\begin{array}{l}\text { knowledge sharing } \\
\text { (Item no 3) }\end{array}$ & $\begin{array}{l}\text { Knowledge sharing by colleagues on informal occasion (Item no } \\
\text { 21) }\end{array}$ \\
\hline Training and guidance & Colleagues wont deceive for own profit (Item no 12) \\
\hline after starting a new & Sharing of knowledge on formal occasion (Item no 17) \\
\hline \multirow[t]{14}{*}{ (Item no 13) } & $\begin{array}{l}\text { College management keen to see knowledge sharing among } \\
\text { faculty (Item no 8) }\end{array}$ \\
\hline & $\begin{array}{l}\text { College management thinks encouraging knowledge sharing } \\
\text { among colleagues is beneficial (Item no 5) }\end{array}$ \\
\hline & Training has improved the performance (Item no 15) \\
\hline & Knowledge sharing by colleagues on formal occasions (Item no \\
\hline & 20) \\
\hline & College management supports and encourages faculty for sharing \\
\hline & knowledge among colleagues (Item no 6) \\
\hline & $\begin{array}{l}\text { Training and development programs are provided on ongoing } \\
\text { basis (Item no 14) }\end{array}$ \\
\hline & Knowledge sharing through written communication (Item no 18) \\
\hline & College management provides necessary resources to enable \\
\hline & knowledge sharing (Item no 7) \\
\hline & $\begin{array}{l}\text { Driven by monetary reward for sharing knowledge with colleagues } \\
\text { (Item no 2) }\end{array}$ \\
\hline & Use of institutional information system or database to share \\
\hline & knowledge(Item no 19) \\
\hline
\end{tabular}


Table 5

Correlational Analysis

\begin{tabular}{llllll}
\hline & $\mathrm{X} 1$ & $\mathrm{X} 2$ & $\mathrm{X} 3$ & $\mathrm{X} 4$ & $\mathrm{X} 5$ \\
\hline $\mathrm{X}_{1}$ & 1 & & & & \\
$\mathrm{X}_{2}$ & $.374^{* *}$ & 1 & & & \\
$\mathrm{X}_{3}$ & $.182^{* *}$ & $.356^{* *}$ & 1 & & \\
$\mathrm{X}_{4}$ & $.241^{* *}$ & $.602^{* *}$ & $.420^{* *}$ & 1 & \\
$\mathrm{X}_{5}$ & $.263^{* *}$ & $.339^{* *}$ & $.369^{* *}$ & $.408^{* *}$ & 1 \\
$* *$ Correlation is significant at the 0.01 level (2-tailed) &
\end{tabular}

Where,

$\mathrm{X}_{1}=$ Reward system, $\mathrm{X}_{2}=$ Top management support

$\mathrm{X}_{3}=$ Trust, $\mathrm{X}_{4}=$ Training and development and $\mathrm{X}_{5}=$ Knowledge sharing behavior

As shown in Table 5, the correlation coefficient between training and development and knowledge sharing behavior is highest followed by trust, top management support and reward system. This indicates the strength of relationship between training and development and knowledge sharing behavior is stronger compared to other independent variables. As all the correlation coefficient is significant at required level of significance, it is referred that there is positive linear relationship between the independent variables and dependent variable included in the study however in order to understand the extent of changes in dependent variable due to change in independent variable, further statistical test needs to be conducted.

The hypothesis of the study is tested using multiple linear regression analysis. The dependent variable is 'knowledge sharing behavior' and independent variables are reward system, top management support, trust, and training and development. The level of significant is 5\% and Entry method is 'Enter' which means all independent variables are entered into the regression model at the same time. Therefore, the model of the study is:

\section{Model Specification}

$\mathrm{KSB}=\beta 0+\left(\mathrm{B}_{1} \times \mathrm{RS}\right)+\left(\mathrm{B}_{2} \times \mathrm{TMS}\right)+\left(\mathrm{B}_{3} \times \mathrm{TR}\right)+\left(\mathrm{B}_{4} \times \mathrm{TD}\right)+\mu$

$\mathrm{KSB}=$ Knowledge sharing behavior

$\beta 0=$ Constant term

$\mathrm{RS}=$ Reward system

$\mu=$ Error term

TMS=Top management support

$\beta 1, \beta 2, \beta 3$, and $\beta 4=$ coefficient of independent

$\mathrm{TR}=$ Trust variables: RS, TMS, TR, \& TD respectively.

$\mathrm{TD}=$ Training and development

The assumptions of multiple linear regressions such as normality of residuals, absence of 
outliers, absence of multicollinearity, and presence of homoscedasticity are ensured through statistical test and analysis which together makes best linear unbiased estimates of the model parameters.

First of all, the outlier was detected and eliminated from the dataset. An outlier is an observation that has a large residual. In other words, the observed value for the point is very different from that predicted by the regression model. As there are two rules of thumb for identifying outliers based on residuals whereby rule no 1 , a conservative method argues that the cases with absolute value of ZRESID (Standardized Residuals) greater than 2 are deemed to be outliers. On the other hand, rule no 2 argues that the cases with absolute value of ZRESID (Standardized Residuals) greater than 3 are deemed to be outliers. Following the second rule, the case no 17, 297, 202 and 220 had absolute value of standardized residuals with 3.135, $3.256,3.574$ and 3.608 respectively and these four cases were eliminated from the study which resulted net sample size of 304 from 308 for the study.

Secondly, the normality of residuals was assessed using one-sample KolmogorovSmirnov (K-S) Test. For this test the null hypothesis $\left(\mathrm{H}_{\mathrm{o}}\right)$ is 'Errors are normally distributed' and alternate hypothesis $\left(\mathrm{H}_{1}\right)$ is 'Errors are not normally distributed'. One sample K-S test showed that the error terms are normally distributed, since p-value of the test was 0.135 i.e., greater than 0.05 .

Thirdly, the homoscedasticity was assessed using null plot, adjacent figure, indicates random pattern or it does not show fanning pattern, therefore there is no problem of heteroscedasticity.

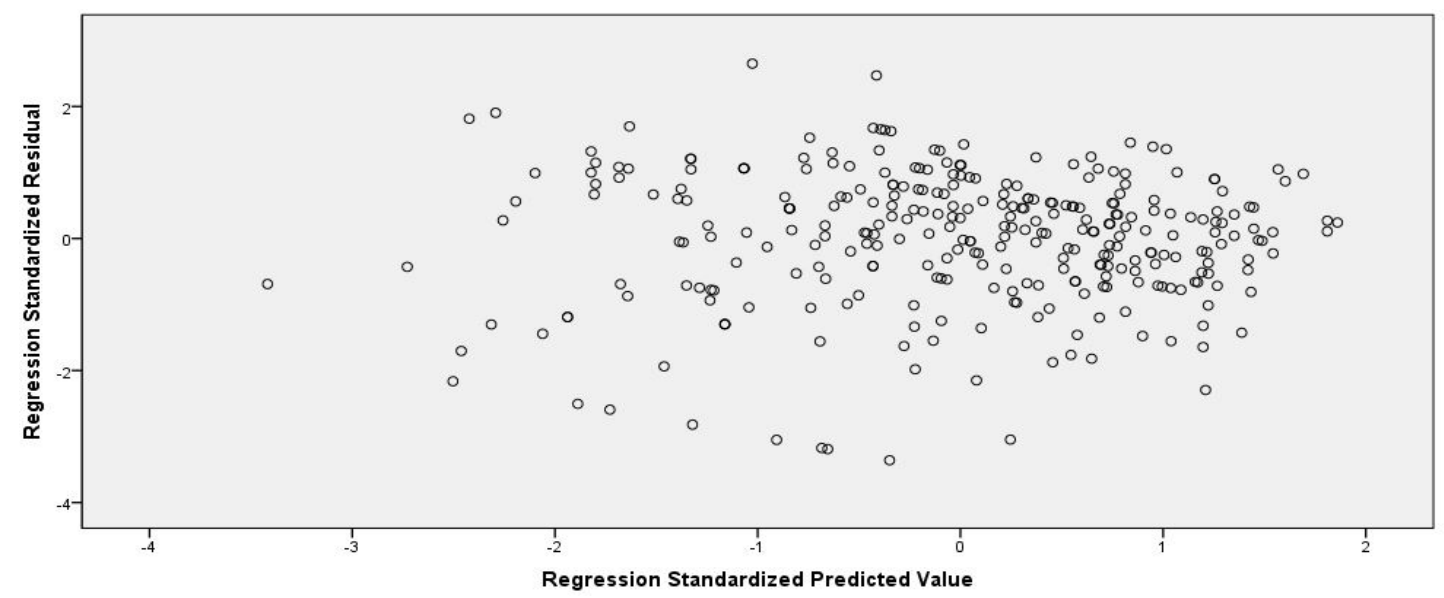

Fourth, multicollinearity was assessed using Variance inflation factor (VIF) because VIF is an indicator of multicollinearity. When VIF exceeds 10 , the variable is said to be highly 
collinear. Since, the values of VIF are all less than 10 and ranges from 1.166 to 1.745 for all predictors so there is no presence of multicollinearity.

\section{Table 6}

Multiple Regression Analysis

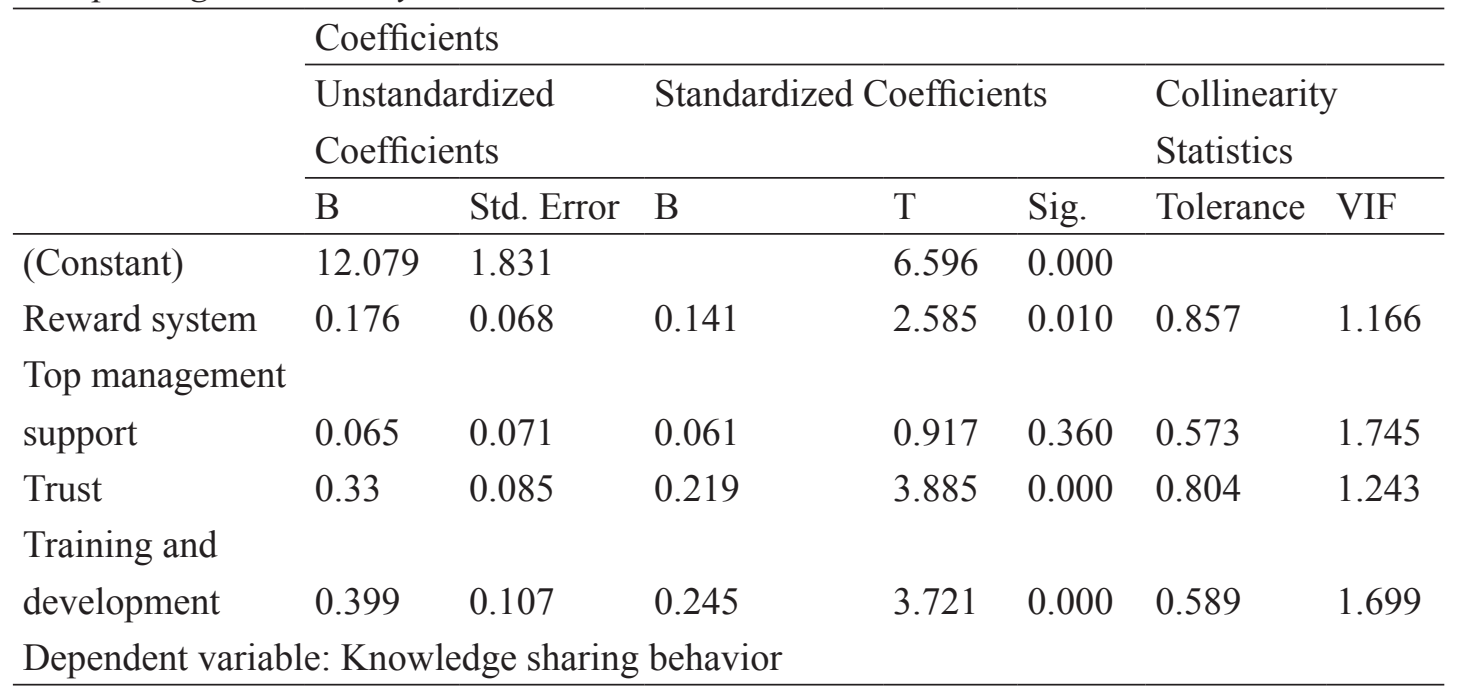

The estimated regression model of knowledge sharing behavior on reward system, top management support, trust and training and development is highly significant, since $\mathrm{F}$ value turned out to be 23.368 and $p$-value $<0.05$. The R-square value turned out to be 0.238 , which means approximately $24 \%$ of the variation in the knowledge sharing behavior, is explained by variation in the independent variables. All slope coefficients are highly significant except for top management support. Since, the estimated coefficient of top management support is greater than level of significance 0.05 ; it should be excluded from the model. However, top management support has been identified as one of the important enablers of knowledge sharing behavior as per theory. On the basis of the summary statistics of the estimated model, the following decision was taken. More, training and development has greater impact on knowledge sharing behavior followed by trust and reward system on the basis of standardized beta coefficient.

The study results confirmed that reward system had a significant and positive effect on the knowledge sharing behavior of faculty members, with the estimated coefficient $(\mathrm{B}=0.176)$ and $\mathrm{p}$ value $<0.05$ significance level. This result suggests that maintaining monetary reward system for knowledge sharing would positively encourage knowledge sharing behavior of faculty member. Thus, Hypothesis 1 reward system positively affects faculty knowledge 
sharing behavior in Nepalese higher educational institutions is supported.

A statistical positive relationship between the top management support and knowledge sharing behavior is found to be insignificant with regression coefficient $(B=0.065)$ and $p>0.05$ level, which leads to the conclusion that Hypothesis 2, Support from top management' positively affects 'faculty knowledge sharing behavior' in Nepalese higher educational institutions, is not supported in the study results.

Hypothesis 3 theorized that, there is positive relationship between 'trust' and 'faculty knowledge sharing behavior' in Nepalese higher educational institutions is supported by the study's data results. The regression coefficient between the two constructs was 0.33 with $\mathrm{p}<0.05$ significance level. The statistical positive relationship indicates that high level of trust of faculty members with their colleagues would encourage them to share knowledge with each other's. The research also supports Hypothesis 4, training and development positively affects faculty knowledge sharing behavior' in Nepalese higher educational institutions, with regression coefficient $\mathrm{B}=0.399$ and $\mathrm{p}<0.05$, indicating that increasing the training and development programs increases the knowledge sharing behavior of faculty members.

\section{DISCUSSION}

What are the key enabling forces among faculty members to share knowledge among their colleagues? was general purpose and result from testing of hypothesis indicated that training and development, trust and reward system as significant predictors of such behavior. The study results confirmed that reward system had a significant and positive linear effect on the knowledge sharing behavior of faculty members with findings consistent to Ramayah and Tan (2014) where the role of monetary incentives to increase the strength of motivation among individuals to share their professional knowledge that in turn intensify useful knowledge sharing was highlighted. Similarly, Naeem, Mirza, Ayyub, and Lodhi (2017) and Kang, Kim, and Chang, (2008) also found a significant positive linear relationship between compensation and reward with knowledge sharing behavior. Nevertheless, Gautam (2012) mentioned "It is not possible every time reward financially to faculties who share their ideas with the colleague and it would be expensive and impossible to monitor and the better way is a soft form of incentives, typically a section of annual performance review in which an individual's contribution to the organizational knowledge is recorded and evaluated.

Tian, Nakamori, and Wierzbicki (2009) found trust as a significant antecedent of knowledge sharing behavior as this study also adopted the same items to measure the 
trust. Furthermore, attributable to Nonaka (1990) it was observed that loyal and trusting relationships eliminate deception, cheating, and the tendency among employees to blame others for organizational failures. A similar perspective on trust was provided by Davenport and Prusak (1998) mentioning that individuals will be more willing to share what they know in an open and trusting culture and the important question is how can organization ensure that it has an open and trusting culture? The importance of training and development programs in knowledge sharing behavior was addressed by several researchers. Ramayah and Tan (2014) argued that the universities' management should encourage informal social gatherings in workplaces for relaxed communication between academics and should also give priority to improving academics' skills and expertise through various workshops and training. Employee training as a predictor of knowledge sharing behavior through the findings of this study was consistent with Kang, Kim, \& Chang (2008).

In the context of knowledge sharing, top management support was conceptualized as the degree to which top management of an organization understands the significance of knowledge management and an extent to which top management was involved in the knowledge sharing practices in the university or an educational institution. It is recognized as an enabler of knowledge sharing as it increases the willingness of faculty members to share knowledge with their colleagues (Tan \& Noor, 2013). This finding is in contradiction with the similar studies (Kang, Kim, \& Chang, 2008; Lin, 2007; Youssef, Saheem, \& Youssef, 2017) that incorporated top management support as enabler of knowledge sharing behavior. Though it is the case, top management support was not proved to be significant predictor of knowledge sharing behavior in the study conducted by Tan and Noor (2013).

\section{CONCLUSION}

This study has attempted to present a unique empirical perspective of Knowledge sharing behavior in the context of higher academic institutions of Nepal. Some key observations through descriptive analysis were, teaching faculty members conceived rewards as an essential motivation for knowledge sharing in general. Second, the level of trust in terms of knowledge, skill, reciprocity and nonexistence of deceive was perceived with higher level of agreement. Third, it was reported lack of enough guidance and training during the initial phase of employment. Apart from these findings, interesting findings came up to explain knowledge sharing behavior. Faculty members share their knowledge actively on informal occasions compared to formal occasion, $\overline{\mathrm{X}}_{1} \overline{\mathrm{X}}_{2}=5.3>4.9$ and correspondingly they perceive 
that their colleagues also share knowledge actively on informal occasion than formal occasion, $\overline{\mathrm{X}}_{1} \overline{\mathrm{X}}_{2}=5.1>4.4$. The correlation analysis indicated that training and development had stronger influence on Knowledge sharing behavior compared to other independent variables, though; all enablers were found to have positive linear and significant relationship with Knowledge sharing behavior. The inferential analysis did not support the significant positive linear relationship between Top management support and Knowledge sharing behavior. However, the reward system, trust and training and development were found to have significant positive relationship with Knowledge sharing behavior. Even though, the effect of Training and development was stronger compared to trust and reward system (standardized $\beta: 0.245>0.219>0.141$ ). Though length of service, employment status, nature of employment and campus type were assumed to be control variable, it was statistically true only for campus type on the basis of findings obtained from independent sample t-test.

\section{Funding Statement}

This work was supported by the University Grant Commission (UGC), Nepal [Award No: MPhil/74_75/Mgmt-5, Young]

\section{REFERENCES}

Adhikari, D. R. (2010). Knowledge management in academic institutions. International Journal of Educational Management, 24 (2), 94-104.

Allameh, S. M., Zare, S. M., \& Davoodi, S. M. (2011). Examining the impact of KM enablers on knowledge management processes. Procedia Computer Science, 3, 1211-1223.

Austin, P. C., \& Steyerberg, E. W. (2015). The number of subjects per variable required in linear regression analyses. Journal of Clinical Epidemiology, 68 (6), 627-636. doi:10.1016/j. jclinepi.2014.12.014

Boateng, H., Dzandu, M. D., \& Tang, Y. (2014). An investigation into knowledge acquisition idiosyncrasies in Ghanaian universities. VINE: The Journal of Information and Knowledge Management Systems, 44 (4), 579-591.

Bock, G. W., \& Kim, G. Y. (2002). Breaking the myths of rewards: An exploratory study of attitudes about knowledge sharing. Information Resources Management, 15 (2), 14-21.

Chalise, M., \& Darroch, J. (2016). Logical empiricism and epistemology of knowledge management: concepts and practices. The Nepalese Management Review, 17 (1), 16-30.

Davenport, T. H. (1997). Information Ecology. Oxford University Press. 
Davenport, T. H., \& Prusak, L. (1998). Working knowledge: How organizations manage what they know. Harvard Business Press.

Drucker, P.F. (1994), “The age of social transformation”, The Altantic Monthly, November.

Gautam, D. K. (2012). Knowledge management initiatives by faculties of Tribhuvan University of Nepal. Int. J. Business Performance Management, 13 (2), 158-167.

Grant, R. M. (1996). Toward a knowledge-based theory of the firm. Strategic Management Journal, 17 (Winter Special), 109-122.

Green, S. B. (1991). How many subjects does it take to do a regression analysis? Multivariate Behavioral Research, 26(3), 499-510. doi:10.1207/s15327906mbr2603_7

Gupta, A. K., \& Govindarajan, V. (2000). Knowledge flows within multinational corporations. Strategic Management Journal, 21 (4), 473-496.

Hansen, M. T., Nohria, N., \& Tierney, T. J. (1999). What's your strategy for managing knowledge? Harvard Business Review, 77 (2), 106-116.

Hill, R. (2008). What sample size is "enough" in internet survey research? Interpersonal Computing and Technology: An electronic journal for the 21 st century, 6 .

Hinkin, T. R., Tracey, J. B., \& Enz, C. A. (1997). Scale construction: Developing reliable and valid measurement instruments. Journal of Hospitality \& Tourism Research, 21(1), 100120. doi:10.1177/109634809702100108

Kang, Y.-J., Kim, S.-E., \& Chang, G.-W. (2008). The impact of knowledge sharing on work performance: an empirical analysis of the public employees' perceptions in south korea. International Journal of Public Administration, 31 (14), 1548-1568.

Kumaraswamy, K. S., \& Chitale, C. (2012). Collaborative knowledge sharing strategy to enhance organizational learning. Journal of Management Development, 31 (3), 308322.

Laal, M. (2011). Knowledge management in higher education. Procedia Computer Science, $3,544-549$.

Lam, A. (2000). Tacit knowledge, organizational learning and societal institutions: An integrated framework. Organization Studies, 21 (3), 487-513.

Lee, J. (2018). The effects of knowledge sharing on individual creativity in higher education institutions: socio-technical view. Admin. Sci, 8 (2).

Masa'deh, R., Shannak, R., Maqableh, M., \& Tarhini, A. (2017). The impact of knowledge management on job performance in higher education: The case of the University of 
Jordon. Journal of Enterprise Information Management, 30 (2), 244-262.

Metcalfe, A. S. (2005). Knowledge management and higher education: A critical analysis. Information Science Pub

Mwape, B. L., \& Mumba, J. (2012). Tools for policy research: AuthorHouse.

Naeem, A., Mirza, N. H., Ayyub, R. M., \& Lodhi, R. N. (2017). HRM practices and faculty's knowledge sharing behavior: mediation of affective commitment and affect based trust. Studies in Higher Education.

Nguyen, L. (2006). Knowledge management trends: Challenges and opportunities for educational institutions. In 16812608211193944897 L. A. Petrides (Author), Knowledge management and higher education: A critical analysis (pp. 21-34). Information Science Pub.

Nonaka, I., \& Takeuchi, H. (1995). The knowledge creating company: How Japanese companies create the dynamics of innovation. Oxford University Press.

Omerzel, D. G., Biloslavo, R., Trnavcevic, A., \& Trnavcevic, A. (2011). Knowledge management and organizational culture in higher educational institutions. Journal for East European Management Studies, 16 (2), 111-139.

Ramayah, T., \& Tan, C. N. (2014). The role of motivators in improving knowledge-sharing among academics. information research, 19 (1), 1-17.

Sohail, S. M., \& Daud, S. (2009). Knowledge sharing in higher education institutions: Perspectives from Malysia. VINE: The Journal of Information and Knowledge Management Systems, 39 (2), 125-142.

Tan, C. N., \& Noor, S. M. (2013). Knowledge management enablers, knowledge sharing and research collaboration: A study of knowledge management at research universities in Malaysia. Asian Journal of Technology Innovation, 21 (2), 251-276.

Tian, J., Nakamori, Y., \& Wierzbicki, A. P. (2009). Knowledge management and knowledge creating in academia: A study based on surveys in a Japanese research university. Journal of Knowledge Management, 13 (2), 76-92.

Youssef, M., Saheem, W., \& Youssef, E. M. (2017). A structural equation model of knowledge sharing behavior in an emerging economy. Journal of Knowledge Management, 21 (4), 925-945. 